\title{
Studying Displaced Karelian Orthodox Women
}

\section{The Interviewees}

My first attempt at getting into contact with displaced Karelian Orthodox women was through a call for written autobiographical submissions that I organized in collaboration with the Finnish Literature Society (FLS). The collection of submissions on the topic of the everyday religion of evacuee Karelian women took place during 2006 and 2007. Quite early on, however, it became clear that it was not going to yield sufficient material for the study. ${ }^{1}$ Thus, when I composed handouts concerning the collection, I included a mention of the possibility of interviews. These handouts I sent to all 24 Finnish Orthodox parishes and to 73 member associations of the Finnish Karelian League. ${ }^{2}$ The campaign resulted in just three people expressing their interest to be interviewed. I acquired two more interviewees from among the women who participated in the collection of written material.

At this point, I had to acknowledge that my approach was not working. There were simply too few potential informants, Orthodox women of evacuee Karelian background, alive for them to respond in great numbers to written announcements. What was required was face-to-face contact with possible participants. During the winter of 2007-2008, I thus made ten visits to meetings of three different Orthodox lay associations in southern Finland. This proved a better strategy; altogether I located 12 of the informants through these meetings. Furthermore, during the autumn of 2008, other researchers of Karelian culture put me in touch with seven more women, mostly from North Karelia. This final addition allowed me to correct the regional bias of the sample of informants so that they would not only represent the South of Finland.

1 The call was addressed to anyone of evacuee Karelian descent. It resulted in altogether $5^{0}$ written submissions, mostly from individuals with a Lutheran background. All the submissions are archived in the Folklore Archives of the FLS.

2 After the Second World War, scores of Karelian associations sprung up to unite the evacuees (Raninen-Siiskonen 1999, 195-215). Several hundred remain active today. 
TABLE 1 List of interviewees and their decades of birth

\begin{tabular}{|c|c|}
\hline pseudonym & decade of birth \\
\hline Anna & 1920's \\
\hline Esteri & 1920's \\
\hline Ilmi & 1920's \\
\hline Katri & 1920's \\
\hline Lempi & 1920's \\
\hline Lyyli & 1920's \\
\hline Martta & 1920's \\
\hline Natalia & 1920's \\
\hline Soja & 1920's \\
\hline Vieno & 1920 's \\
\hline Elsa & 1930's \\
\hline Faina & 1930's \\
\hline Hilja & 1930's \\
\hline Rauha & 1930's \\
\hline Senja & 1930's \\
\hline Siiri & 1930's \\
\hline Toini & 1930's \\
\hline Auli & 1940's \\
\hline Elvi & 1940's \\
\hline Kirsti & 1940's \\
\hline Raili & 1940's \\
\hline Sinikka & 1940's \\
\hline Tarja & 1940's \\
\hline Maija-Liisa & 1950's \\
\hline
\end{tabular}

Overall, I interviewed 24 women (see Table 1). The selection of informants does not accurately reproduce the demographics of Finnish Orthodox women aged 60 or older. However, the variation within the sample guarantees that it includes both more and less typical representatives of this particular group of people. I alternate between calling the interviewees displaced Karelian and evacuee Karelian Orthodox women, in reference to both their religious affiliation and historical background. All the interviewees had been baptized and socialized into the Orthodox Christian faith as children. In addition, their family history was tied to that of the people forced to leave Finnish Karelia 
during or after the Second World War. While individuals with a connection to the evacuations from Karelia nowadays often speak of themselves simply as Karelians, I have opted to use more precise terms instead. The reason for this is that, even though the evacuations took place a long time ago, the informants' descriptions of their post-war experiences take up an important role in my analysis. Thus, I have wanted to distinguish them from people with other Karelian backgrounds and identities.

The Finnish language term referring to Finns who during or after the Second World War migrated permanently to other parts of Finland from what was to become Soviet Karelia is siirtokarjalainen, which literally translates as "transferred Karelian." Nonetheless, I employ the term "evacuee Karelian" instead, for it better captures the circumstances of the relocation in question. ${ }^{3}$ The term "displaced Karelian," moreover, I use to emphasize the fact that the evacuees were, in actuality, internally displaced persons. In Finland, the term Karjalan pakolainen, which translates as "displaced Karelian" or "Karelian refugee," is commonly used of people who came from Russian Karelia to Finland in the aftermath of the Russian revolution. It is important not to confuse the two groups of migrant Karelians with each other. Here, however, this will not constitute an issue, since I am only discussing the evacuees of the Second World War.

The average age of the women at the time of the interviews was 75 years. Their mean birth year was 1933, with the eldest interviewees born in 1920 and the youngest informant in the mid-195o's. Prior to the Second World War, the families of 20 of the women lived in Border Karelia (see Illustration 1). ${ }^{4}$ The family of one woman lived in the Karelian Isthmus. Furthermore, the parents of two women started their families only after the Second World War; each of these women had one parent from Border Karelia. One woman was the result of her Border Karelian mother's war-time romance and never knew her biological father.

3 Strictly speaking, war-time evacuations did not cover the exact area later ceded to the Soviet Union. Some of the Karelian evacuees could therefore actually return to their homes after the end of the war, whereas other people had to relocate from their homes only at that time; that is, when the peace treaty was put into force (Sallinen-Gimpl 1994, 12).

4 The Border Karelian home municipalities of the interviewees (or their parents) were as follows: Impilahti one, Korpiselkä one, Salmi seven, Soanlahti two, Suistamo three, and Suojärvi nine informants. On the eve of the Second World War, nine in ten inhabitants of Salmi were Orthodox, as were two in three inhabitants of Suojärvi, Suistamo, and Korpiselkä (Hämynen 1993, 237-341). In Soanlahti and Impilahti, Lutherans slightly outnumbered the Orthodox. 




ILLUSTRATION 1 Map of Karelia

Karelia has never formed an independent nation-state. Instead, the geographical area of Karelia has been varyingly divided between Sweden/Finland and Novgorod/Russia/ The Soviet Union since the 14th century. As the border has been redrawn, conceptions of Karelia and Karelians have changed as well. Map designed by Tiina Aaltonen. 
The parents and grandparents of all the interviewees were Orthodox, save for one woman, whose mother and maternal grandparents were Lutheran. The women had between one and nine siblings, five on average. For half of the interviewees, their childhood families also included other members of their kin, commonly the father's parents or mother. At the same time, one interviewee lived as a foster child among childless relatives, and another was raised by her grandmother.

In pre-Second World War Karelia, the families of a great majority of the informants were smallholding farmers. Other occupations of their fathers included teacher of a village school, truck driver, gravedigger, and forest ranger. After the war, the parents of most of the interviewees set up a new farm on the land allocated to them by the government. The two sets of parents who established their families at this time also obtained their livelihood from smallholdings. In those families that had not owned a farm prior to the war the fathers found other employment. A few of the women, moreover, lost their fathers in the war. In these cases, the mother commonly initially moved to live with her parents and later remarried. In addition, one of the women was orphaned during the war and moved in with her sister's family.

In the course of the Second World War period, residents of Border Karelia and the Karelian Isthmus were twice (in the winter of 1939-40 and in the summer of 1944) evacuated from their homelands which had turned into war zones. 20 of the 24 women had personally experienced at least one of these evacuations. Ten of the informants had experienced both. The others were spared two evacuations for various reasons: some had not been born at the time of the first evacuation, for others their parents never returned to Karelia after the first evacuation, whereas the oldest interviewees no longer lived with their childhood families at the time of the second evacuation and had moved outside the evacuation zone. Of the four women who did not take part in the evacuations at all, three were born only after the second evacuation. One of the women was born after the first evacuation and her family did not return to Karelia so she was spared the second evacuation as well.

The basic education of 13 of the interviewees consisted of primary school (six years), whereas 11 of them had completed secondary school (five years). Four informants had also graduated from upper secondary school (three years), three of whom had achieved university degrees. In the interviews, several of the women noted that they had not been able to continue to secondary or upper secondary school due to the lack of money. Most of these women, however, had later continued their education in community colleges or evening classes.

Although most of the women came from farming families, only one of them became mistress of a farm in adulthood. The majority worked in the social and 
service sectors, a few also in industry. The women's occupations included childminder, cleaner, cooker, entrepreneur, factory worker, hairdresser, librarian, nurse, seamstress, secretary, shop clerk, teacher, and youth worker. Whereas some had lifelong careers, many had experience of various lines of work. Only a few of the informants had been housewives for the greater part of their adult lives. Several women also worked outside the home while their children were under school age, even though most of them had their children at a time when the Finnish system of public welfare services, such as the right to public day care, was not yet operative.

All the women were married to Finnish citizens, men from various parts of the country. The informants' marriages took place between the 1940's and 70 's, the average age of marriage being 23 years. Twelve of the couples settled down within a hundred kilometers of the capital, whereas nine lived in North Karelia or North Savonia (the region to the west of North Karelia), and three lived elsewhere in Finland. One half of the couples lived in bigger cities, the other in smaller towns and rural communities. Furthermore, 22 of the 24 interviewees had children. The number of children to these women varied between one and five, the average being three. The children were born approximately between 1945 and 1985; the average age for giving birth to one's firstborn was 25 .

The husbands of 20 interviewees were members of the Evangelical Lutheran Church, and those of four belonged to the Orthodox Church. In the course of the marriage, the Lutheran husbands of two informants left their Church and joined the civil registry. In addition, one Lutheran husband converted to Orthodoxy in old age. The children of the women with Orthodox husbands were all baptized into the Orthodox faith. However, of the 18 women who were married to Lutheran men and had children, 16 had all their children baptized into the Lutheran faith. In two families, the older children were baptized into the Lutheran faith and the younger children into the Orthodox faith. In one of these families, this was due to a change in the legislation concerning the freedom of religion (see discussion in the section on Orthodox-Lutheran marriages). In the other, it resulted from the fact that, by the time of their birth, the father had left the Lutheran Church. Incidentally, also in the second family where the father left the Lutheran Church, changes in the overall religious composition of the family ensued. Afterwards, the mother organized the conversion of all the children into the Orthodox faith.

The conversions mentioned above all took place when the interviewees' children were underage. Three of the women had witnessed one of their children converting to Orthodoxy as a personal choice in adulthood. One woman's Lutheran child had become a Pentecostalist. It is possible that some of the women had also children that had left the Lutheran or the Orthodox Church to join the civil registry, although this did not come up in the interviews. 
At the time of the interviews, 15 of the 24 informants were widows. Four remained married to their original spouses, whereas five were divorced. In all cases the divorce had occurred only when the children were in their late teens or older. None of the widows had remarried, but one of the divorcées had recently gotten engaged. Furthermore, all the living children of all the informants had reached adulthood; the oldest women had children who had already retired. All the interviewees who had borne children had also become grandmothers.

Moreover, at the time of the interviews, all but two of the women were retired. Many had been so for over a decade, even two decades. All of them still lived at home, with the exception of one who lived in a retirement home. Most lived alone, although some continued to live with their husbands, and a few had one of their adult children living under the same roof. The women's physical condition and overall activity, however, varied quite a lot: while two women still worked full-time, three were practically house-bound due to their illnesses. Most interviewees fit somewhere between these two extremes. Some led quite busy lives with various hobbies, whereas for others one activity outside the home in a week was enough. Many suffered from a chronic illness or condition, or several.

\section{The Research Process}

The vignette of my visit to Anna's home, with which the book opens, describes the typical course of the interviews. I interviewed each informant once, and the interviews were conducted one-on-one at their homes. Excluding those interviewees who I met at Orthodox lay association meetings, my initial contact with all the women was by telephone. At the agreed date of the interview, I traveled to their home town or neighborhood; some of the women came to pick me up at a local railway station or bus stop. Often, the informant had prepared a snack or a meal, which we ate before the start of the interview. The women also showed me around their homes, pointing out photographs and memorabilia. As I got my papers arranged, we discussed the research project, the weather, how my trip had gone, their homes, health, and families, or possibly some topical news. After the interview was over, we again chatted casually and might have something to eat. I made an effort to end the meetings in an unhurried way. This gave the informant the chance to digest the interview a bit before my leaving, and to ask any question that came to her mind.

The average length of the interviews was two hours 20 minutes. They were recorded with an mp3 recorder, save for one where the recorder was accidentally not switched on. Before the start of every interview, I explained 
to the interviewee how the interview material would be treated in the future: the archiving of the recordings into the Folklore Archives of the FLS, FLS policies concerning the storage and use of the recordings (see Suomalaisen Kirjallisuuden Seura 2010), and my own commitments. Three of the interviewees did not agree to the archiving of their recordings, but, nevertheless, gave me permission to hold on to and to make use of them. Overall, the study complies with the Finnish Advisory Board on Research Integrity guidelines for responsible research conduct (see Finnish Advisory Board on Research Integrity 2013).

At the beginning of the interview process, many of the ideas I had concerning the research were not yet clearly formulated. I was interested in lay women's everyday religion, in how significant life events and developments in the overall surroundings were reflected in religious practice, and in remembering as a feature of religion. Thus, I started interviewing with the overall aim of eliciting information about the women's religious life histories. The greater part of my interview frame (see Table 2) proceeded chronologically, focusing on accounts of everyday religious practices, memories of special religious events, as well as interpretations of the significance of religion during different life phases. The last sections of the interview outline, however, contained questions that aimed to capture informants' perceptions and assessments concerning the Orthodox religion as well as Orthodoxy in Finland. All in all, the questions were not designed to establish an exhaustive picture of the religious practices and beliefs of the interviewees, but to provide a basic framework within which they could reflect on their religiosity.

TABLE 2 List of interview themes

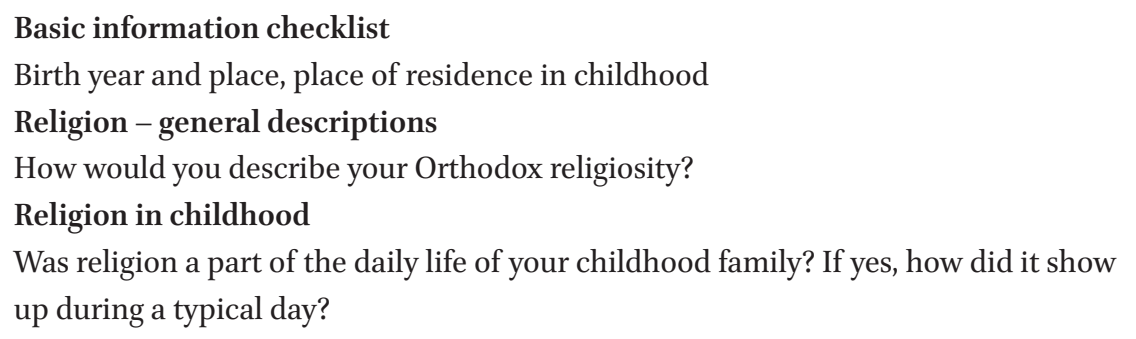

Evacuations and their effects

What happened to your family during the wars?

Religion in adult life

How did you and your husband take care of the religious upbringing of your children? Was there something about religion that you absolutely wanted to teach your children? If yes, what and why? 
TABLE 2 List of interview themes (cont.)

\section{Religion today}

Has your religious practice changed during recent years? If yes, how and why?

Religion - reflections and interpretations

Is there an Orthodox custom or ritual that is particularly close to your heart? If yes, why this custom or ritual?

Displaced Karelians and the continuity of traditions

What does your Karelian heritage mean to you today?

\section{Concluding questions}

Why did you decide to take part in this interview?

THE LIST INCLUDES ONE OR TWO SAMPLE QUESTIONS ON EACH THEME.

The interviews varied a great deal in both form and content. Some of them quite closely followed a basic question-answer structure. In these interviews, the informants' speech was characterized by a conscious attempt to provide an answer to the very question that I had posed. I was able to quite closely follow the interview outline, since the women expected me to introduce themes for them to reflect on. Other interviewees, however, approached the interview situation with a different attitude. They answered to my questions with lengthy autobiographical narratives, moving independently from one topic to another. In these interviews, I usually let the informant take the lead, but tried to gently conduct the discussion towards themes of particular interest to me. Rather than providing the basis for the interview, the interview outline functioned as a checklist to keep track of the major themes I wanted to address during the discussion.

There were certain topics, such as childhood, war, and family, to which the women commonly responded with spontaneous and lengthy narratives. The chronological structure of the interview outline also guided the women to talk about these themes, often providing an orientation for the whole interview. By contrast, several informants were clearly uncomfortable with the more theologically oriented, evaluative questions introduced in the latter part of the interview. They tended to pass over these quickly, or even refrain from answering altogether. All in all, some women openly cited the opportunity of talking about their childhood experiences and the lives of their parents as their primary motive for taking part in the interview. Others, for their part, harbored a more general interest in Karelian and Orthodox culture, which they also wished to discuss with me.

In the interview situations, generally speaking, a warm and easy atmosphere prevailed. The interviewees seemed to relate to me as half researcher, 
half young acquaintance or distant relative. The age difference between the interviewees and myself emphasized an epistemological relationship in which the former were the party in possession of knowledge. I appeared ignorant but eager to learn. This kind of an interviewee-interviewer relationship is often considered advantageous when it comes to the production of ethnographic descriptions and knowledge (e.g., Spradley 1979, 50). On occasion, however, the difference in our ages made the women doubtful over whether I could relate to their experiences. "The young people today have no idea," several of them began when speaking, for instance, of the poverty of the first post-war years.

For the majority of the women, it was important to learn of my religious and ethnic background. At some point, they commonly asked me whether I was Orthodox or Karelian. I am neither; instead, I come from a Lutheran Finnish family with no ties to Karelia. Hearing this, some of them appeared baffled at my interest in studying Karelian Orthodox people. I, for my part, was surprised that my background mattered so much to the women - a reaction that betrays my habitus as a member of the religious majority. Nevertheless, speaking about their religion to a non-Orthodox, particularly to a Lutheran, was a familiar situation to the women. Most of them had Lutheran relatives, including husbands, children, and grandchildren. This does not erase the fact that my background made me firmly an outsider in their eyes. Ultimately, the women's accounts constitute a performance of one's Orthodox identity in front of the Lutheran other.

In several previous interview-based studies on Karelians, researchers have reported how their own Karelian background created common ground between interviewer and interviewee (e.g., Loipponen 2010, 124-142; RaninenSiiskonen 1999, 66-69). I had no such shared history with my informants. As far as I can tell, however, they spoke freely to me of their Karelian background. Naturally, it is also possible that my non-Karelianness affected the women's readiness to talk about their negative experiences concerning their displacement and resettlement. In this vein, both ethnologist Pirkko Sallinen-Gimpl and historian Heli Kaarina Kananen have made note of Karelian evacuees' overly positive and integration-oriented speech, connecting it to their need to fit into post-war Finnish society (Kananen 2010, 208-215; Sallinen-Gimpl 1994, 223-228).

Orthodoxy and Karelianness were the two social categorizations that, in the interview situations, mattered most to the women. They were loaded categories, packed with significance. Altogether, I listened to 24 women talk passionately about their religion and ethnicity; this resulted in me becoming increasingly aware of these layers of my own habitus as well. In the course of the interviews, that is, I became a conscious witness to the workings of my embodied dispositions regarding both religion and ethnicity. Here, I shall address the latter issue. 
Although I have lived all my life in southern Finland, both my parents are from South Ostrobothnia (a region in western Finland), and my family has a strong Ostrobothnian identity. Initially, I thought that this would provide me and the informants with common ground: just like them, I, too, cherished an emotional connection to one of the "Finnish tribes." I soon realized, however, that Ostrobothnians did not have a good reputation among the women. South Ostrobothnia was the region where a lot of the Orthodox had initially been evacuated, and several women noted that the locals had treated them cruelly. To most of the women, then, I never mentioned my roots, fearing that doing so would distance me from them. Instead, I identified myself as a Southerner.

Throughout the research process, I had a sort of love-hate relationship with the women as Karelians. On the one hand, I could well relate to the pride they felt over their Karelian ancestry. On the other, I had to struggle with an irrational antipathy towards their Karelianness, with a part of me resenting "all these Karelians" for thinking that they are better than "us Ostrobothnians." My troubled relationship with Karelianness led me to decide, early on in the research, not to focus as much on the Karelian identity of the women as I had initially intended. In Bourdieuan vocabulary, I feared that I would not be able to separate myself sufficiently from the struggles within the "ethnic field" to produce a scientific analysis of it (see Bourdieu 2010). What further justified this decision was my realization that I was learning very little about evacuee Karelian identity that had not already been said in previous research on the topic (e.g., Raninen-Siiskonen 1999).

The interviews resulted in 55 recorded hours of conversation. The recordings were transcribed in their entirety to facilitate their systematic analysis. Four of the interviews I transcribed myself, whereas the other 18 recordings were transcribed by two research assistants. The transcripts were done verbatim, showing colloquial and dialect features and including repetitive words, intervening sounds, and pauses. Altogether, the interview transcripts amounted to 790 pages of writing with approximately 2,600 characters (no spaces) per page. ${ }^{5}$

Once the interviews were transcribed, I used the computer-assisted qualitative data analysis software ATLAS.ti to go through the transcripts. I organized the material into thematic codes based on topics of discussion, developed a more nuanced system of coding that classified the women's descriptions about their practices, beliefs, experiences, and opinions concerning religion, and

5 As auxiliary research material, I have used my field notes of the interviews and visits to Orthodox lay association meetings, answers of the 11 women somehow affiliated with Orthodoxy from the FLs collection of writings, and two additional interviews of women baptized into the Lutheran faith but with Orthodox, Border Karelian mothers. 
created a layer of codes that focused on the dimensions of conversation and interaction. In addition, I tagged features of the interviewees' accounts that seemed to engage, in one way or another, with the theoretical notions that I had found intriguing. The total number of codes came to about 500. After the coding was completed to an adequate extent, I drew up analyses of about 150 of the codes. Little by little, I started working these into larger totalities: adding contextual information, theoretical and methodological discussions, perspectives I wanted to cover, and problems I wanted to address. To complete the process of analysis, I also returned to reading the entire interview transcripts. With this final task, I wanted to confirm that my code-based interpretations were reflective of the overall material.

While processing, coding, and analyzing the material, I developed the theoretical underpinnings of the research. Initially, I was to combine the approaches of oral history and social memory research to look into how sociologist of religion Danièle Hervieu-Léger's (2000) conception of religion as a chain of memory was realized in the displaced Karelian Orthodox women's meditation on religion. After a while, however, I grew dissatisfied with this plan. I felt that it tied me to going through the forms and contents of the women's explicit reminiscences in the interview situations, whereas I wanted to be able to approach the intertwinement of remembering with religiosity as such. Thus, I became attracted to accounts of social memory that emphasized its embodied aspects (e.g., Connerton 1989; Narvaez 2006), as well as to accounts of agency focusing on its temporal and embodied constitution (e.g., Emirbayer and Mische 1998; McNay 2000).

At some point, a researcher colleague introduced me to the work of Pierre Bourdieu; this became the determining moment as to the course of the whole research. I was particularly inspired by Bourdieuan theory of habitus, immediately feeling that it resonated well with the interview material. Habitus seemed to provide me with the link between religious practice and embodied memory that I had been looking for. Moreover, although I originally conceived of habitus as a theory of embodied social memory, gradually the role of social memory research in the study dwindled. Instead of understanding Bourdieu's theory as a "fruitful perspective from which to approach the topic of social memory" (Kupari 2011, 218), I came to see it as a fruitful perspective from which to approach lived religion.

Far into the research process, I felt myself oscillating between material and theory. I was torn between my loyalty towards the richness of the informants' accounts and my desire to be able to say something theoretically relevant about their case as a whole. It was not until I had written up most of the analysis that I was able to strike a balance in this issue. The crucial thing to do, I realized, 
was to formulate the theoretically inspired research objectives in a way that they respected the nature and limits of the material. Thus, I decided to focus on the "lifelongness" of the religion of the women with the help of Bourdieu's concept of habitus.

I discuss the women's habitus as a type of class habitus, based on Bourdieu's (199ob, 6o; 1984, 123-124) notion that the habitus of individuals will share similar qualities if their overall position in social space coincides in some respect. Ultimately, however, no two habitus are identical. Thus, when I speak of the women as displaced Karelian Orthodox women, the result is a generalization that does not apply with similar accuracy to all the informants (see also Doucet and Mauthner 2002, 131-132). In writing up the analysis, I have held in check the inevitable reduction of the women's accounts by doing two things. First, even though my emphasis is on locating common features of the women's habitus, I make note of differences and exceptions as well. Second, I keep a respectful distance with regard to the interviewees' individual life stories by not disclosing too much information of any of them, even in a thoroughly anonymized form.

While I have taken precautions not to invade the women's privacy, I have also strived to depict them as flesh-and-blood human beings. The ideal, following Bourdieu (1999b, 625), is to give readers the means to "situate themselves at the point in social space from which all the respondent's views over that space emanate, which is to say that place in which this particular worldview becomes self-evident, necessary, taken-for-granted." Inevitably, the picture I present of the women's life-worlds falls somewhat short of this ideal (see Alldred and Gilles 2002, 149). Nevertheless, it is a valuable picture, capturing an essential facet of their religiosity.

\section{Locating Displaced Karelian Orthodox Women in Social Space}

\section{Religion, Gender, and Old Age in 2oth and 21st Century Finland}

In 1920, at the time of the birth of the oldest of my interviewees, Finland was a newly independent country (since 1917) which had just emerged from a civil war (fought in 1918). On the eve of the Second World War, the majority of the Finnish working population was still involved in agriculture and forestry. After the war, however, Finland went through an intensive structural change involving large-scale modernization, urbanization, industrialization, and expansion of the service sector (Jokinen and Saaristo 2006, 83-88). The "flight from the countryside" reached its peak in the 1960's and 70's, when baby boomer 
children reached adulthood and moved to the centers of southern Finland, or to Sweden, to find a living (Jokinen and Saaristo 2006, 88-89, 93-97, 148-149). ${ }^{6}$

According to sociologist Jeja-Pekka Roos $\left(1987,51^{-59}\right)$, what is characteristic of the life narratives of Finns born in the 1920's and 30's is the stark contrast between the poverty of their childhood years and the growing stability and prosperity of later life. The people of this generation were born in the countryside, but often later moved to towns where they worked hard to secure good living conditions for their children. Later on in life, they were able to enjoy the fruits of their labor themselves, for instance, in the form of different conveniences. Roos's account also applies to the life narratives of the Orthodox women. In my material, however, even the women born in the 1940's emphasized the poverty of their childhood homes in contrast to their later living conditions. After all, their families had often lost virtually everything when leaving Karelia.

The particular characteristics of the Finnish gender order reflect the living conditions of a small, poor, and agrarian population (Julkunen 1999, 86). In pre-modern, rural Finland, the family and the household were organized along a patriarchal order. However, in everyday life men and women often appeared primarily as partners in shared toil, both with their areas of responsibility (Löfström 1998, 241-243; Pylkkänen 1999, 26-30). Over the second half of the 19th century, the conception of men and women as polar opposites with separate but complementary life spheres began to gain ground among the Finnish bourgeoisie. During the inter-World War period, this ideal also spread among other social classes. Housewifery never became the norm for women of the peasantry or the working class, however, as their input as workers was essential to the survival of the family (Löfström 1998, 249-250; Pylkkänen 1999, 30-37).

In Finland, as in many other Western countries, the end of the Second World War brought the cult of domesticity briefly to the fore (Löfström 1998, 251; Olsson 2011, 61-67). This period, however, was swiftly over. In step with the modernization of the society, women's entry into paid workforce became more and more common. Starting from the 196o's, this move was spurred by the development of the social welfare system, including maternal (later parental) benefits and children's public daycare. Since that time, the conception of women as working mothers has been decisive in defining the position of women within Finnish society (Julkunen 1999, 79-80, 87-90; Tammelin 2009, 40-43). Nevertheless, even in contemporary Finland women shoulder more

6 In Finland, the term "baby boom generation" refers to the cohorts born between 1945 and $195^{\circ}$ (Savioja et al. 2000, 58-60). 
responsibility than men when it comes to taking care of the home and the family, and consequently have more difficult time in fitting together the demands of their domestic and working lives (Julkunen 1999, 92, 94; Pylkkänen 1999, 37; Tammelin 2009, 109-110). Overall, the past five decades have been characterized by a reduction in the average number of children born to Finnish couples, a growth in the divorce rate, and the overall proliferation of different family models (Jokinen and Saaristo 2006, 147-148, 193-199). The role of the family in the lives of Finnish people has, nonetheless, remained central.

The population of Finland has aged rapidly in recent decades. In 2015, the number of Finnish people at least 65 years of age amounted to 20 percent of the population (Statistics Finland 2016). Behind this overall demographic trend is a decline in the mean birth rate after the baby boom cohorts, as well as an increase in the average life expectancy. Moreover, all through the past century, Finnish women have lived on average several years longer than Finnish men. Thus, in 2015 there were about 150,000 more women than men in the age group of the displaced Karelian Orthodox women: that is, aged 65 or older (Martelin, Pitkänen, and Koskinen 2000, 53-56; Statistics Finland 2016).

The aging population translates into a growing demographic ratio of dependency which has been seen to constitute a challenge to Finnish society, its public healthcare, welfare, and pension systems. On a different note, recent research has shown that both the physical and the material well-being of the elderly have continued to improve (Jyrkämä 2001, 268-269, 304-307, 312-313; Statistics Finland 2013, 1-2). The average Finnish life-span includes more years of good health than before, whereas the mean length of the so-called deep old age (the time of serious illness, frailty, and dependence on others) has not increased.

At the turn of the 2oth century, the population of Finland was very homogeneous with regard to religious affiliation. In 1920, 98 percent of the people belonged to the Evangelical Lutheran Church (Kääriäinen, Niemelä, and Ketola 2005,82 ). The Finnish religious field, however, was not as unified as this statistic suggests. The strong influence of Pietistic revival movements in many parts of the country caused friction within the Lutheran Church simultaneously as it was losing its unquestioned status as the source of individuals' morals, beliefs, and lifestyles. Participation in church functions was declining, and Finns were increasingly divided up into those actively involved in congregational life and those alienated from the Church (Heininen and Heikkilä 1996, 209-210, 213218; Kääriäinen, Niemelä, and Ketola 2005, 49-59).

During the Second World War, this development was temporarily halted, to an extent. For instance, the number of people frequenting church functions grew (Heininen and Heikkilä 1996, 247). However, in the 1950's secularization 
processes gained pace, and, particularly during the 6o's social activity, the Lutheran Church became the target of open criticism (Heininen and Heikkilä 1996, 238-241; Kääriäinen, Niemelä, and Ketola 2005, 60-61). Since these first post-war decades, the Church has slowly reformed its structures, often amid considerable debate. The ordination of women, for example, became possible in 1986, several decades later than in some other Nordic countries (Utriainen, Salmesvuori, and Kupari 2014, 6). Moreover, towards the turn of the 21st century the Church began to take a more active role in secular society, participating in current discussions and intensifying its contribution in the field of welfare work (Helander 1999, 70-73; Kääriäinen, Niemelä, and Ketola 2005, 61; Moberg and Sjö 2012, 83).

Leaving the Evangelical Lutheran Church has become more and more common throughout the 2oth century down to the present day. Whereas in 1950, 95 percent of Finns were members of the Lutheran Church, in 2000 the percentage was down to 85 , and by 2014 it had fallen to 76 (Kääriäinen, Niemelä, and Ketola 2005, 82, 88-92; Statistics Finland 2015b). However, and in line with the "believing in belonging" paradigm of the Nordic countries, membership in the Lutheran Church is often still considered a part of the national identity (Bäckström 2015, 158-159; Kääriäinen, Niemelä, and Ketola 2005, 84-85).

According to surveys, Finns' belief in core Christian doctrines remained on the same level during the last decades of the 2oth century. Participation in church functions, however, was low throughout the century and further diminished over the course of time (Kääriäinen, Niemelä, and Ketola 2005, 98-120). All in all, sociologists of religion describe the religiosity of Finns at the turn of the 21st century as characterized by increasing individualism (Kääriäinen, Niemelä, and Ketola 2005, 166-175; Ketola 2008, 347-349). Over the past three decades, religious plurality in Finland has increased markedly, a development that is only partly due to increased immigration (Kääriäinen, Niemelä, and Ketola 2005, 62-80; Ketola 2008, 338-345; Utriainen, Salmesvuori, and Kupari 2014, 8-9).

In Western societies, modernization has been responsible for major reconfigurations concerning both gender and religion. Recently, several sociologists of religion have argued that the experience of modernization was very different for women compared to men, and that these differences had crucial consequences in the field of religion (Marler 2008, 4-7; Woodhead 2007, 577-580). In a word, while modernization had a secularizing effect on men, the same was not true with women. Rather, as men's interest in religion waned, women took charge of the religious life of the family and of passing on family traditions to the children (Vincett, Sharma, and Aune 2008, 4-5; Woodhead 2007, 578-579). The pattern in which women acted as preservers of religion and 
upholders of traditional values remained in place, to a marked extent, until the Second World War. In fact, sociologist of religion Linda Woodhead (2007, 571-580) has argued that women felt the impact of secularization in a significant way only after they, too, entered the labor market in substantial numbers during the post-war decades.

As regards Finland, survey material shows that Finnish women continue to demonstrate more attachment to traditional religion than men. More women than men belong to the Evangelical Lutheran Church, consider religion an important aspect of their lives, believe in basic Christian teachings, and are active in both their public and private religious practice (Kääriäinen, Niemelä, and Ketola 2005, 134-144; Statistics Finland 2015a). Moreover, the same statistics also indicate that increase in all these measures of religiosity correlates with age. Wartime acts as an important dividing line: those born before the Second World War clearly demonstrate more attachment to religion than the generations born after the war. These two trends combined effectively make women born before the Second World War - a group that includes the majority of the women of my study - as the most religious group of people in Finland today.

\section{Orthodoxy in Finland - Historical Developments}

Between 1809 and 1917, Finland was a Grand Duchy of the Russian Empire. A great majority of the Orthodox citizens of Finland were living in Ladoga Karelia, Border Karelia, and North Karelia. In Border Karelia, the generality of the population was Orthodox (Koukkunen 1981, 290-292; see also Martikainen and Laitila 2014, 155-157). Karelia had been under the influence of Orthodox Christianity since the beginning of the second millennium. During the time of the Grand Duchy, the religion of Orthodox Karelians was a fusion of Russian Orthodox and older ethnic traditions, with many pre-Christian features surviving even into the 2oth century (Martikainen and Laitila 2014, 153-155; Stark 2002, 11-14, 34-39). The sustaining of this folk religion was facilitated, first and foremost, by the remoteness of the region. Well into late 19th century, priests' visits to many areas were rare, which encouraged people's initiative, selfdirectedness, and interpretative activity with respect to religion (Laitila 1998, 384, 388, 393-395; Stark 2002, 36-37).

The 19th century saw the rise of nationalism in Europe. ${ }^{7}$ One front where the interests of the nationalistically minded Finnish and Russian administrations clashed openly was Border Karelia. From a nationalistic point

7 In Finland, a central catalyst for the process of carving out a distinct national identity was the publication of Kalevala (first edition 1835), a compilation of epic poetry collected mostly 
of view, the identity of Border Karelians was contestable: their religion was seen to connect them to Russians, their language to Finns (Laitila 1998, 387393; see also Hämynen 1995). Simultaneously, the idea of a Finnish Orthodoxy distinct from Russian Orthodoxy gained ground among the Finnish speaking Orthodox clergy. This propelled the founding, in 1885, of the Brotherhood of Ss. Sergius and Herman, a home mission dedicated to the education of the Finnish Karelian Orthodox (Laitila 2006, 159-160).

After the October Revolution, in December 1917, Finland declared independence. The administration of the newly independent republic considered it important to secure the allegiance of the Orthodox minority to the state. Thus, in 1918, the Orthodox Church received a standing similar to that of the Evangelical Lutheran Church. In 1923, moreover, the Church severed its ties with the Patriarchate of Moscow and joined the canonical jurisdiction of the Patriarch of Constantinople (Loima 2004, 159-162). During the 1920's and 30's, different aspects of Church life underwent a process of nationalization. Also the Julian calendar was abandoned in favor of the Gregorian one, as used by the Lutheran Church; a change that caused controversy in some Border Karelian parishes (Laitila 2006, 161-165; Loima 2004, 150-178).

In the first decades of independence, parish life in Border Karelia intensified. Furthermore, the Brotherhood of Ss. Sergius and Herman invested in Sunday schools, lay association gatherings, festivals, and publishing activity (Koukkunen 1982, 48-55; Laitila 1998, 402-404). These activities, however, proceeded hand in hand with the secularizing influences of modernization. In addition, after independence the eastern border was closed, which cut off Border Karelians' contacts with their Orthodox neighbors in Soviet Karelia. At the same time, Lutheran presence in the area grew due to increasing migration from other parts of Finland (Laitila 2006, 165; Laitila 1998, 395, 402-406).

The Winter War began on November 3oth 1939, when the Red Army invaded Finland in the Karelian Isthmus, and lasted until March 1940. In the 1940 Peace of Moscow, Finland agreed to cede to the Soviet Union most of Finnish Karelia (Jutikkala and Pirinen 2003, 436-444). The Continuation War began in late June 1941, a few days after the German onslaught on the Soviet Union. Finnish troops quickly advanced beyond the pre-war borders and occupied large areas of Soviet Karelia. After almost three years of stagnated war, in June 1944, the Soviets began a heavy attack on the Karelian Isthmus and forced Finnish troops to retreat. In the Armistice of Moscow in September 1944 (the terms of which were confirmed in the Paris Peace Treaties in 1947), the border of the

from Russian Karelia. Karelia received a mythical status as a land where the ancient, authentically Finnish culture and religion could still be encountered (Sihvo 1999). 
1940 treaty was mostly reconfirmed: Finland lost virtually all of the Karelian Isthmus, Ladoga Karelia, and Border Karelia, as well as the area of Petsamo in Lapland, and parts of the municipalities of Salla and Kuusamo in north eastern Finland (Jutikkala and Pirinen 2003, 444-456).

Immediately when the Winter War started, residents of Karelian borderlands had to leave their homes ahead of advancing Soviet troops. They were evacuated in chaotic circumstances to other parts of Finland. In parts of Border Karelia, for instance, people had only an hour to prepare - and the residents of some easternmost villages not even that much, as they were stranded behind enemy lines and spent half a year in internment in Soviet Karelia (Hämynen 2008, 28-29; Kirkinen, Nevalainen, and Sihvo 1994, 436-439). After the peace treaty was signed, the remaining residents of ceded areas were given a few weeks to relocate. However, the continuing warfare in Europe, and the tightening of cooperation between the Finnish and German governments, gave Karelians hope that their home areas could still be reclaimed (Hämynen 2008, 31-35; Raninen-Siiskonen 1999, 12-13).

For the Finnish Orthodox Church, the terms of the 1940 peace treaty were harsh. The Orthodox heartlands in Border Karelia were left on the wrong side of the border. Two-thirds of the Orthodox population, about 55,00o people in total, were among the displaced Karelians. 17 of the 28 Orthodox parishes had also been evacuated, as well as all four Orthodox monasteries. It has been calculated that the Church lost about go percent of its wealth in the Winter War (Koukkunen 1982, 34, 59; see also Husso 2011, 36-51). During 1940-41, the evacuated parishes continued to function in new circumstances as best they could. When Finnish Karelians began returning to their old homes in the autumn of 1941, Orthodox parishes were quick to follow (Koukkunen 1982, 62-64, 70-73; Laitila 2006, 165-167).

In June 1944, evacuations were necessary once again. This time around, they were permanent. In 1950, the evacuated Orthodox parishes were abolished, and new ones were established in the areas where Orthodox Karelians had resettled. Gradually, churches and other facilities essential for the functioning of the new parishes were constructed, funded by the state (Koukkunen 1982, 123-129; see also Husso 2011, 52-148). Nevertheless, throughout the first post-war decades the Orthodox Church had a hard time providing services for its members. There was a shortage of Orthodox infrastructure, priests, and qualified teachers of Orthodoxy as a school subject (Koukkunen 1982, 100-129; Laitila 1998, 412-413; see also Kananen 2010, 162-189). Overall, the hardships caused by the war took a severe toll on the Orthodox community and its self-esteem. During the first post-war decade, the Church lost almost ten 
percent of its members (Huttunen 2002, 197-198; Kärkkäinen 1999, 204, 209; Laitila 2006, 168-169).

The evacuees from all ceded areas amounted to 430,000 people, about 11 percent of the country's total population. About 407,000 of these were Karelians (Sallinen-Gimpl 1994, 12). In 1945, the Finnish government enforced a land acquisition act that guaranteed arable land to those evacuees whose pre-war subsistence had come from agriculture. The resettlement plan took into account the ecological and social conditions of the evacuees' pre-war surroundings (Kirkinen, Nevalainen, and Sihvo 1994, 470-478). In the plan, Border Karelians were mainly placed in North Karelia and North Savonia. Although the resettlement area was geographically unified, it was so vast that the population was scattered very widely (Hämynen 2008, 39).

The evacuees experienced the full range of treatment from the local population. Initially, they were often assigned housing in private homes, which created a ground for conflicts as well as close bonding. Later on, strain was caused by the implementation of resettlement strategies: part of the land given to evacuees was confiscated from private owners (Hämynen 2008, 39-41; Kirkinen, Nevalainen, and Sihvo 1994, 473-474). Cultural differences between newcomers and locals were marveled at by both parties (Sallinen-Gimpl 1994). In the end, evacuees often had no choice but to adapt to the ways of their new home areas.

The greatest cultural rift was between the Orthodox evacuees and the Lutheran locals. The post-war atmosphere emphasized national homogeneity, and the Orthodox religion was often regarded with suspicion, as something Russian. For the Orthodox evacuees, the pressure to fit in with the majority was great. Consequently, many distinguishing features of Orthodoxy lost at least some of their importance during the first post-war decades (Hämynen 2011, 216-218; Heikkinen 1989, 326-334; Kananen 2010, 63-101, 190-196; RaninenSiiskonen 1999, 162-165). Nevertheless, the dominant discourse concerning the resettlement emphasized how the whole process went smoothly. As Heli Kaarina Kananen (2010, 17-20, 66-68) has argued, the negative experiences of the Orthodox evacuees were not given due treatment at the time, because they did not fit together with the ideal of a unified and harmonious nation propagated in resettlement narratives. The issue of discrimination against the Orthodox has received serious attention in academic research only relatively recently (e.g., Kananen 2010; Raninen-Siiskonen 1999; see also Hämynen 2008).

In the 1960's, the public image of the Orthodox faith, as well as the selfesteem of the Orthodox community, began to ameliorate. The change was due to growing contacts with different cultures and the overall unravelling of the 
homogeneous national culture (Laitila 2009, 343-347; Laitila 2006, 169-170; see also Kananen 2010, 215-254). Furthermore, by that time the Orthodox Church had mostly concluded its rebuilding process, and was thus able to direct energy from its core functions to other pursuits (Koukkunen 1982, 134, 140; Laitila 2006, 170-173). These included the promotion of knowledge of different features of Orthodox culture, such as iconography and pilgrimage, among the Church's membership and, to some extent, even the general public (Huttunen 2002, 198-199; Sidoroff 1984, 30-32). In the 1970's, moreover, the functioning of the New Valamo monastery (named after the original Valaam monastery situated on an island in Lake Ladoga, evacuated during the Winter War) was improved by the construction of a new main church. The monastery began to attract more visitors, and the brotherhood new members (Martikainen and Laitila 2014, 164).

During the first post-war decades, the Orthodox Church was still very much a Karelian Church. Over time, the connection between Orthodoxy and Karelianness has diminished. Since the 1970's, however, some features of ethnic Karelian Orthodoxy have become the target of projects of revivification. In addition, some Karelian Orthodox customs have been taken up by the tourism industry - particularly to represent North Karelia, the exotic east of present-day Finland (Martikainen and Laitila 2014, 172-173; Paasi 1995, 128-132; Petrisalo 2001, 64-106; Raivo 1996, 205-238).

Over the course of time, the standing of Orthodox Christianity in Finland has become more and more stable. For example, around and after the turn of the 21st century, the Church has enjoyed mostly (although not entirely) positive publicity in the media (see Laitila 2015)..$^{8}$ In present-day Finland, Orthodoxy is commonly viewed as part and parcel of the increasingly multicultural, multivocal, and heterogeneous Finnish culture (see Kääriäinen, Niemelä, and Ketola 2003, 144-145; Martikainen and Laitila 2014, 170). At the same time, Lutheran influence is evident in the organization, functions, and policies of the Church (Laitila 2009, 342-343; Laitila 2006, 174-175; Sidoroff 1984, 29-30). In comparison with other Eastern Orthodox Churches, the Finnish Church thus appears more liberal and open to modern influences (e.g., Binns 2005, 23; McGuckin 2008, 74).

8 Unlike its Evangelical Lutheran counterpart, the Orthodox Church has not actively participated in public discussions concerning ethical issues (Jääskinen 2006, 271-274; Laitila 2006, 175). Thus, while the Lutheran Church has, in recent years, gotten tangled in several public debates concerning, for example, the rights of sexual minorities, the conservative views of the Orthodox Church have not received similar attention (see Laitila 2015; Moberg and Sjö 2012, 86-89). 
Membership in the Finnish Orthodox Church decreased throughout the second half of the 2oth century. Whereas in 1940 there had been 80,000 Orthodox, in 1960 Church membership was down to 69,000, and in 2000 to 57,00o (Hämynen 1996b, 27; Huttunen 2002, 198; Statistics Finland 2015b). However, since then, the Orthodox population has risen slightly. In 2014, the Church had 62,000 members, 1.1 percent of the total population (Statistics Finland 2015b). This increase is mainly due to two factors: migration and conversion to Orthodoxy. Ever since the 1970's, the number of individuals joining the Church has exceeded that of individuals leaving it (Nguyen 2007, 123-124; see also Ortodoksinen kirkko 2016). Moreover, since the go's a crucial factor in keeping up this trend has been immigration from Russia and Eastern Europe. Thus, in 2009, already 11 percent of the Church's members were foreign-born (Martikainen and Laitila 2014, 166-167).

Finally, throughout the second half of the 2oth century, the regional composition of the Orthodox Church was greatly affected by urbanization (Paukkunen 1989, 19, 23-25; Sallinen-Gimpl 1994, 25-26). In 2015, one-third of the Finnish Orthodox belonged to the parish of Helsinki (Ortodoksinen kirkko 2016). However, the provinces of North Karelia and North Savonia continue to boast the highest density of Orthodox, over two percent of the total population throughout the area (Hämynen 2011, 206-215; Kärkkäinen 1999, 199, 209; Raivo 1996, 170-174, 179-180).

\section{Orthodox-Lutheran Marriages in Post-Second World War Finland}

Marriages between Orthodox and Lutherans have occurred in Karelia for centuries. However, it was not until the first decades of the 2oth century, as industrialization brought more and more Lutherans to Border Karelia, that their number grew to include a significant proportion of all Orthodox marriages (Hämynen 1996a, 105-109). After the resettlement of Karelians to other parts of Finland, the number of these so-called mixed marriages rose to unprecedented heights. ${ }^{9}$ In the $1950^{\prime}$ 's, almost 90 percent of all the marriages of Orthodox Finns

9 The term "mixed marriage" (seka-avioliitto) denotes a marriage between two people who differ from each other in some way considered meaningful in a given culture (Breger and Hill 1998, 7). I use it to refer to marriages between Orthodox and Lutheran Finns. The term can be criticized for its negative connotations and for being too vague. However, as it is generally used of Orthodox-Lutheran marriages within the Finnish Orthodox community, and did not receive criticism from the informants, I have decided to use it here.

In Orthodox Christianity, mixed marriages are a theologically problematic issue. According to Orthodox canon law, marriages between Orthodox and non-Orthodox Christians are prohibited (Patsavos and Joanides 2000, 434-437). Faced with the worldly reality of interchurch 
were to Lutherans, and the percentage stayed essentially the same for the rest of the century (Hämynen 1996a, 95; Huotari 1975, 12; Merras 1993, 87).

The tight intertwinement of the Orthodox minority with the Lutheran majority has been an important factor in the life of the Finnish Orthodox community ever since the Second World War. Most crucially, mixed marriages have had major effects on the constitution of the community. They were the central reason behind the drop of Orthodox Church membership rates throughout the latter part of the 2oth century, for most children born of mixed marriages were baptized into Lutheranism (Huotari 1975, 90, 225; Kananen 2010, 179-183; Makkonen 2011, 278-280, 298-305). In addition, marriage to a Lutheran led many Orthodox, especially women, to convert to the Lutheran faith.

According to the 1922 law on the freedom of religion, in place until 1970, a child was to follow the father's religious affiliation unless the parents agreed otherwise in a written statement (Uskonnonvapauslaki 1922). In many parts of the country, it was quite common to make such statements in favor of the Lutheran Church (Huotari 1975, 164; Kananen 2010, 202-204; Piiroinen 1978, 62-63). Children with Orthodox fathers were baptized into Lutheranism, because the Lutheran mother was adamant, or because the Orthodox father thought it better for the child to become a Lutheran. The all-time low point for Orthodox baptisms was right after the Second World War. In the 1940's, only about 17 percent of the children from Orthodox-Lutheran marriages were baptized into the Orthodox faith (Huotari 1991, 29; Huotari 1975, 158-165). By the 1970 's, the percentage had risen to 30 .

In 1969, the law on the freedom of religion was reversed so that, from 1970 onwards, a child was to follow the mother's religious affiliation unless otherwise decided by the parents (Laki uskonnonvapauslain muuttamisesta 1969). This did not significantly alter the statistics concerning the total percentage of Orthodox baptisms (Huotari 1975, 162, 171-172). The amendment was, in any case, significant. The previous practice had created a situation in which most Orthodox children grew up with Lutheran mothers, whereas Orthodox mothers had Lutheran children, and this had been seen to constitute a problem for the building of Orthodox consciousness among youth (e.g., Lehmuskoski 1979, 327; Merras 1993, 97-99; Piiroinen 1980, 25-26). ${ }^{10}$

marriages, the Finnish Orthodox Church has conceded to follow a non-categorical interpretation of the canon law as regards them (Hämynen 1996a, 95; Merras 1993, 88-93). 
In light of the above information, it is possible to compare the religious affiliations of the children of the Orthodox women of my study to the legislation in place at the time of their birth. Of the 18 informants with children with a Lutheran husband, 14 gave birth to all their children before 1970. In all these marriages, save for one (the exception mentioned in the section on the interviewees), the children were originally baptized into the Lutheran faith. Two of the women gave birth to all of their children after the law changed. The children of these two were, nevertheless, baptized into Lutheranism after the father. Finally, two women had their older children before and their younger children after the law reform. In one of these families, the younger children were also baptized into Lutheranism, whereas in the other they were baptized into Orthodoxy.

In his dissertation Ortodoksin ja luterilaisen avioliitto (Orthodox-Lutheran Intermarriage), theologian Voitto Huotari (1975; see also 1991) investigates Orthodox-Lutheran marriages in Finland. The study, based on the quantitative analysis of interviews of married couples, paints an interesting picture of the dynamics within mixed marriages during the first post-war decades. In Huotari's (1975, 9, 56, 132, 180-181) material, the co-existence of the Orthodox and Lutheran faiths in one family often resulted in a bias towards the majority tradition. The Orthodox spouses, that is, experienced a push to adapt to the customs of their Lutheran partners. Moreover, Huotari's analysis also shows that a large part of the religious activities of the families were usually dictated by the affiliation of the children. As Lutheranism was the affiliation of choice for the offspring of most couples, this trend further reinforced the bias towards Lutheranism.

Huotari's research includes also interesting observations concerning gender. According to his analysis, women in mixed marriages were both more prone to overall religious interest and more ready to adapt to their spouses' religion than men (Huotari 1975, 150-157). Huotari's sample includes, on the one hand, twice as many families that were oriented solely towards the husband's denomination than families oriented towards the wife's denomination. On the other, it was not infrequent for the wife to be the sole religiously active partner in a marriage, attuned to both religions. Of all the parties of these marriages, Orthodox women were particularly likely to resign their own practices in favor of Lutheran ones. They, in fact, appeared to be even more interested in Lutheranism than their Lutheran spouses (Huotari 1975, 138-140). Although Huotari does not make this explicit, it is clear that Orthodox women's special relationship with Lutheranism is related to the Lutheran affiliation of their children. This interpretation is further legitimated by yet another facet of Huotari's $(1975$, 112, 172-173) analysis: in his material, mothers were more active in the religious upbringing of children than fathers. 
All in all, Huotari's $(1975,225)$ conclusion is that mixed marriages had a Lutherinizing effect on Orthodoxy in Finland. Marriage to a Lutheran loosened Orthodox individuals' ties to traditional Orthodox practices and beliefs (Huotari 1975, 112-125). This finding has recently been taken up by MarjaLiisa Honkasalo (2015) in her ethnographic study of North Karelian Orthodox Christian women in interfaith marriages. In this study, she argues that such marriages were particularly challenging for the belief system of Orthodox women, since their traditional religious role was so centered on the home as a sacred space. Not being able to perform this role fully could result in a chronic state of ambiguity and crisis, and a sense of being failed as an Orthodox practitioner (Honkasalo 2015, 86).

Above, I have produced a brief outline of the religious and social environment within which the women of my study had, over the course of their lives, practiced religion. This overview describes selected features of the Finnish religious field. In addition, it provides information concerning the social trajectories of particular groups of people in 2oth and 21st century Finland: women of the inter-World War generation, Orthodox Christians, displaced Karelians, and women in Orthodox-Lutheran marriages. This background information is crucial to understanding the habitus of these groups of people - and, ultimately, that of my interviewees (see Bourdieu 1984, 123-124). 